Investigaciones Fenomenológicas, n. 9, 2012, 367-382.

e-ISSN: $1885-1088$

\title{
Acceder a la fenomenología de Marc Richir. Algunas CLAVES HERMENÉUTICAS PARA LA RECEPCIÓN DE RICHIR EN ESPAÑA
}

\author{
Pablo Posada Varela \\ Bergische Universität Wuppertal, Alemania - \\ Université Paris-IV-Sorbonne, Francia \\ pabloposadavarela@gmail.com
}

¿Para qué un texto más de "presentación" de Richir (texto, que a mayor abundamiento en el absurdo, es postrero) si ya disponemos de estos magníficos tres textos? Los tres textos que han precedido a estas líneas ya hablan por sí mismos. ¿Para qué añadir algo? ¿Para qué si, de hecho, consideramos que estos tres textos de Richir que aquí hemos traducido ya han cumplido, bastante mejor de lo que pudiera yo mismo hacerlo aquí, una labor de introducción ${ }^{1}$ a algunos elementos nodales de su fenomenología? ¿Qué sentido tiene añadir estas palabras a los propios textos de Richir así como a la labor de explicitación conceptual acometida en no pocas notas de traducción a estos textos, notas en las que, por lo demás, he remitido, a través de vínculos internet, a otros textos de o sobre Richir? A ello hay que sumar algunas de las contribuciones presentes en este mismo número de Investigaciones fenomenológicas. Pues bien, precisamente a tenor de lo dicho, la labor de presentación que las líneas siguientes

\footnotetext{
${ }^{1}$ Remitimos al nutrido y variado contenido de la extraordinaria página web montada por Sacha Carlson: www.laphenomenologierichirienne.org. Por lo que hace a una exposición de los conceptos fundamentales de la fenomenología de Richir, y en espera de la tesis doctoral de Sacha Carlson, codirigida por Guy van Kerckhoven, que trata sobre el conjunto de la obra de Richir con una profundidad, precisión y exhaustividad hasta ahora inauditas en el panorama de la bibliografía richiriana, hagamos especial referencia a su excelente trabajo, publicado en el número 34 (2010) de Eikasia y por lo tanto disponible en línea: Sacha Carlson: "L'essence du phénomène. La pensée de Marc Richir face à la tradition phénoménologique".pdf (Tesina, Universidad Católica de Lovaina -Louvain-la-Neuve-), 1997. También puede consultarse, creo que con provecho, la siguiente presentación general de la fenomenología de Richir: Pablo Posada Varela, "En torno a la singladura filosófica y fenomenológica de Marc Richir".pdf, Eikasia 40 (2011), así como otros trabajos incluidos en los números especiales 34 y 40 de la revista Eikasia, ambos dedicados a Marc Richir. No dejemos de citar, por último, el libro de Alexander Schnell, de publicación reciente: Le sens se faisant. Marc Richir et la refondation de la phénoménologie transcendantale, Bruxelles, Éditions Ousia, 2011, y del que puede encontrarse una traducción del índice analítico de contenidos en el no34 (2010) de Eikasia.
} 
acometen incide en un plano que no es el de la explicitación conceptual, sino, todo lo más, el de cierta contextualización. Entendemos aportar unas pocas claves y apuntes útiles, según creo, a cualquier tipo de explicitación meramente conceptual. Claves hermenéuticas que, sin menoscabo alguno, podríamos calificar de extrínsecas. Por extrínsecas que sean no dejan, con todo, de ser decisivas; de ser, a mi parecer, claves.

\section{RICHIR Y SUS CONTEMPORÁNEOS}

Suele elevarse una rotunda queja, a veces hasta indignada, en punto a la excesiva dificultad de la obra de Richir. Sea. Mas una vez esgrimida, mucho queda por decir. Es queja que tiene, claro está, su razón de ser. Ahora bien, se trata de situar correctamente su legitimidad, de ahí que hayamos de volvernos hacia las raíces de esta dificultad. Lo que es mera y muda impresión de dificultad puede y debe matizarse de varias maneras.

Para empezar, sorprende en los libros de Richir $-y$ creo que es una de las razones de su dificultad- esa falta (quizá excesiva) de género alguno de concesión a la simplificación. Eso (volveremos sobre ello enseguida) es sobre todo patente en ese medio de transmisión de su pensamiento que son sus libros. Medio de transmisión -a eso vamos- que no es, precisamente, el único. Lo importante -i.e. a lo que Richir jamás renuncia cueste lo que cueste- es la profundidad del tema fenomenológico, la cosa misma, de ahí que rara vez haya momentos muertos en la lectura, pasajes sin tensión, meandros superficiales. La tensión de dificultad está casi uniformemente repartida, muy convenientemente estibada. En todos los pasajes se está intentando decir algo. No hay meandros hueros $y$, en el recodo de un párrafo, una frase de una densidad inexpugnable. En realidad, en los libros, todo es bastante denso. Lo que no hay son diferenciales de densidad.

Efectivamente, en cada página sorprende la enorme ambición intelectual que hay y el continuo compromiso con la profundidad. Ahora bien, se trata de una profundidad que no se entiende como muda y abisal, sino que alberga la pretensión de ser articulada. Richir también tomaría, con Ortega, la defensa del teólogo frente al místico. 
Por lo demás, siendo la obra de Richir, como es ya, bastante extensa, rara vez se repite. Es algo que puede comprobar cualquiera. Se dicen cosas distintas y las cosas parecidas se dicen siempre de una muy distinta manera.

A estos rasgos primeros que enunciamos se suman otros elementos que son otros tantos ingredientes que fraguan esta sensación de dificultad, de inaccesibilidad, impresión superficial más allá de la cual conviene adentrarse. Sería largo hacer un recuento más o menos exhaustivo de todos estos ingredientes. De hecho, hacerlo con exhaustividad sería, todo lo más, un interesante ejercicio de psicología y de sociología, pero no (o no siempre) de filosofía.

Así pues, renunciando a que esto se convierta en el exclusivo tema de estas breves líneas más allá de haber sido su espita, añadiría también un rasgo que diferencia a Richir de muchos de sus contemporáneos (coetáneos o no, por retomar la distinción de Ortega) y que creo que también es responsable de la dificultad y el rigor de su obra pues, acostumbrados como estamos al estilo de la fenomenología de sus contemporáneos francófonos, Richir socava el suelo de nuestras apercepciones, trastoca muchas de nuestras expectativas. Nos estamos refiriendo al modo en el que Richir se desmarca de la "retórica" de sus contemporáneos fenomenólogos. Sobre todo de los del ámbito francés. No procede del mismo modo que sus contemporáneos y esa extemporaneidad nos cambia, como lectores, el paso. Despista, en suma, que no haya, en Richir, una retórica de la "superación". Superación de la metafísica o de la ontoteología. Ese deseo no preside a su obra como sí es el caso para otros fenomenólogos que parecen haber interiorizado el gesto heideggeriano y la prolongación que éste tiene en Derrida. En rigor, no tiene sentido -cree Richir- querer superar nada. Menos aún tener en mente una suerte de ley de transitividad según la cual, como muchos piensan en voz baja sin atreverse a enunciarlo (pues no son tan necios para no sospechar la fantasía y el infantilismo que habitan tamaña quimera), valdría algo así como lo siguiente: si Heidegger "supera" a Husserl, y si Derrida "supera" a Heidegger y uno "supera" a Derrida (o consigue arreglárselas para no ser deconstruido), entonces -ioh maravilla!- iuno los habría superado a todos! Esto último, fantasía que no pocos fenomenólogos (se diga lo que se diga) tienen en mente (sobre todo, repito, en el panorama francés), es una aberración. Una aberración que en el trance se cobra, claro está, la completa obliteración de la obra de Husserl, del inmenso tesoro de profundidad y 
precisión que se esconde en sus páginas. Este punto nos lleva directísimamente al siguiente.

\section{UN ELEMENTO DIFERENCIAL FUNDAMENTAL:}

RICHIR Y LA PACIENTE ASIMILACIÓN DEL LEGADO DE HUSSERL

Efectivamente, he ahí otro elemento diferencial estrictamente consectario de lo anterior. Pues bien, ese elemento constituye otra de las razones de la dificultad de Richir: su paciente y profunda lectura de Husserl (que poco tiene que ver con la repetición de textos una y otra vez comentados: huelga decir que Richir se distingue por ello también de muchos otros husserlianos ortodoxos al uso que para él, por cierto, no son ni merecen el nombre de verdaderos husserlianos). Y esto es, evidentemente, otro de los puntos que más distingue a Richir del resto de la fenomenología en lengua francesa, panorama en el que, como se sabe, ya todos superaron, hace tiempo, al viejo Husserl, mero capítulo de la Historia de la Metafísica Occidental.

Uno de los méritos de Richir reside, en cambio, en no creer que Husserl sea un mero capítulo más de nada. Su mérito reside en haberse tomado radicalmente en serio la obra del fundador de la fenomenología; y haberla tomado con la paciencia que exige la atención a la calderilla fenomenológica.

De ahí que cumpla reseñar el hecho de que, junto a su labor de autor, Richir haya emprendido una gran labor de editor e incluso de traductor (anticipado) de muchos textos y revisor de traducciones para la versión final de éstos. Así, en la colección Krisis, que dirige, han aparecido importantes traducciones de algunos tomos importantes de Husserliana. Traducciones a las que Richir, más allá de haberse limitado, como director de colección, a haber acordado su plácet, ha contribuido de forma bastante directa (no todos los directores de colección pueden decir lo mismo respecto de las traducciones en lengua francesa; de hecho, no todos tienen la competencia suficiente en Husserl para hacerlo). Contribuciones directas que, por ejemplo, se saldaban con interminables discusiones sobre terminología con su equipo de traductores. De ahí que, dicho sea de paso, sienta Richir una gran admiración por el enorme trabajo que, desde 
hace años, lleva acometiendo Antonio Zirión en relación a su diccionario Husserl inmanente y diccionario de traducción ${ }^{2}$, admiración por la enorme precisión y probidad intelectual de sus traducciones de Husserl al español. Si bien Richir no firma directamente esas traducciones en Krisis como traductor principal, todas están revisadas por el propio Marc Richir, cuando no anticipadas en parte. Anticipadas en libros, artículos o cursos que comentaban largos pasajes citados en el cuerpo del texto (de los libros, o de los artículos ${ }^{3}$ ) o detenidamente explicados en sus cursos (la editorial Ellipses proyecta una edición en varios volúmenes de los cursos de Richir sobre Husserl). Textos que, sólo disponibles en el original alemán, Richir se había ocupado de traducir antes de que apareciese la traducción del tomo entero o se lanzase siquiera el proceso de traducción.

Por sólo citar algunos ejemplos, encontramos, en la colección Krisis de la editorial Jerôme Millon, las traducciones de los textos complementarios a las lecciones sobre la conciencia interna del tiempo de 1905 (Hua X), los tomos sobre síntesis pasiva (Hua XI) y síntesis activa (Hua XXXI), los manuscritos de Bernau (Hua XXXIII), el tomo sobre la representificaciones intuitivas, i.e. sobre la phantasia, el recuerdo y la conciencia de imagen (Hua XXIII), la recopilación de textos sobre la reducción (Hua XXXIV) y algunos otros que están en curso de traducción como, por ejemplo, el tomo que contiene el curso Einleitung in die Philosophie (Hua XXXV). Eso sin contar con la traducción de otros autores de la tradición fenomenológica (como Fink o Patočka) o afines a ella (como Binswanger o Erwin Strauss).

Yo le debo a Richir haber accedido a territorios casi desconocidos de la obra de Husserl. Recuerdo, por caso, extraordinarios cursos dedicados a la Va Meditación cartesiana, leyéndola al detalle y proponiendo una traducción inédita de la misma que discutía en clase y que, en ocasiones, llevaba escrita y repartía antes. Recuerdo valiosísimas clases sobre algunos textos de Bernau u otros del tomo sobre Phantasia (recuerdo, por ejemplo, un curso entero, extraordinario, que estuvo casi exclusivamente dedicado al comentario del texto no2 de Hua XXIII). Clases muy anteriores a la aparición de las traducciones de los citados

\footnotetext{
${ }^{2}$ Richir pidió expresamente, de hecho, que hubiera un vínculo permanente al diccionario de Husserl de Zirión desde la página web de www.annalesdephenomenologie.org creada, una vez más, gracias a la generosidad de Sacha Carlson. Siente un enorme respeto por ese proyecto y, desde luego, tiene en cuenta y hace uso de ese maravilloso diccionario como ineludible instrumento de trabajo.

${ }^{3}$ Son tantos los ejemplos que llevaría varias páginas enteras hacer el recuento. Correspondería casi a dos tercios de la bibliografía richiriana. Tan sólo me queda remitir, una vez más, a la página web montada por Sacha Carlson www.laphenomenologierichirienne.org
} 
tomos de Husserliana y desde las que, precisamente, empezaron a fraguarse, en el equipo de traductores de la colección Krisis, los proyectos de traducción completa. Fueron cursos, por lo demás, clarísimos, y donde el cotejo con el texto alemán era continuo. Efectivamente, la mayoría de las veces era el propio Richir quien, al inicio de la clase, nos repartía su propia proposición de traducción de los párrafos que fuera a comentar.

3. VARIEDAD DE REGISTROS (LIBROS, ARTíCULOS, CONFERENCIAS, CLASES, ENTREVISTAS, CONVERSACIONES ACLARATORIAS)

He aquí otro punto, pues acabamos de mentar la labor de Richir como profesor, que acaso merezca una breve alusión. Efectivamente hay, en Marc Richir, registros de discurso, de transmisión filosófica, sorprendentemente diferenciados, lo cual, sin prejuzgar de la oportunidad o no de ello, no es el caso de otros filósofos que, por ejemplo, hablan (a veces maravillosamente) pero no escriben o que "leen" en sus clases o conferencias sus escritos, que hablan, en suma, como escriben. No hay pues aporte de lo uno sobre lo otro ni auténtica alimentación recíproca. No ocurre esto en Richir. Cada registro hace su aporte y es necesario al otro como complemento sin que -nos atreveríamos a decir- ninguna de ellos sea el fundamental. De ahí que sea especialmente absurdo, en el caso de Richir, remitir a la obra fundamental, a una supuesta suma phaenomenologica ${ }^{4}$. Están, de un lado, los libros, largos y en los que Richir se permite afrontar las dificultades sin escatimarlas, tomándose todo el tiempo y espacio requeridos. Pero estos libros no se entienden si no se complementan con otros textos más accesibles y que tratan, a veces, de cuestiones menos nodales pero que hallan riquísima expresión en variados elementos de ciertas instituciones

\footnotetext{
${ }^{4}$ Muchas veces me han hecho esa pregunta personas que querían empezar a introducirse en la obra de Richir. Pregunta que era algo así como: "pero vamos a ver, ¿cuál es el libro fundamental de Richir? ¿qué es lo que hay que haber leído?", pregunta que sin ser exactamente la misma guardaba también estrecha relación con esta siguiente, que también he oído repetidas veces de boca de algunos amigos: "¿por qué libro empezar?", "¿cuál es el acceso más fácil?". Tras haberle dado vueltas a la cuestión, a día de hoy aconsejaría empezar por los artículos. Por artículos como los que aquí se publicarán (que creo que constituyen un muy buen acceso). Y acaso acompañar esas lecturas de algunas grabaciones de sus cursos y conferencias, no bien estén éstas disponibles. De haber procedido así, creo que me hubiera ahorrado no poco tiempo y esfuerzo. Por lo que hace a la primera de las preguntas, creo, sencillamente, que no hay respuesta. No existe la obra fundamental. $O$, si se quiere, tantos son los ángulos de entrada, que la respuesta a esa pregunta ha de dejarse determinar por el camino de pensamiento que sea el de cada quien. No existe, en Richir, algo así como la obra fundamental en sí.
} 
simbólicas. Ya en el capítulo de los libros están los libritos Le corps. Essai sur I'intériorité (Hatier, 1993), Melville. Les assises du monde (Hachette, 1996), o La naissance des dieux (Hachette, 1998). Acaso también un libro ya terminado y que aparecerá dentro de un tiempo, La contigence du despote (con alguna que otra interesante alusión a Ortega y a Machado por cierto) y que profundiza las cuestiones ya tratadas en Du Sublime en Politique (Payot, 1992), suerte de fenomenología de la historia, de lo político. Ya cursa, en esos libros, un registro expositivo distinto. Evidentemente, también son testimonio de lo variado de la temática richiriana. Ahora bien, a todo eso se suman los artículos. Artículos o pequeñas contribuciones a obras colectivas como los tres que nos ocuparán en breve.

A este respecto, me parece de enorme importancia reseñar que la mayoría de los artículos no están retomados en libros. Sólo una levísima parte lo está. La ventaja de los artículos estriba en que Richir no presupone, en ellos, conocimiento de su obra. Ni siquiera - caso de algunos de ellos- conocimiento profundo de la obra de Husserl. Hay artículos, como lo son, en parte, los que ahora presentamos, en los que el propio Richir hace tabula rasa proponiéndose, en un espacio relativamente breve (a que el formato libro no constriñe), la exposición de un punto de su fenomenología o de la fenomenología de Husserl (u otro autor) a la luz de sus intereses. En esos artículos asoma el enorme talento pedagógico que siempre ha presidido a sus cursos y conferencias y que, a pesar de lo que el registro discursivo de los libros deja presumir, es enorme. Gracias al esfuerzo de Sacha Carlson muchos de esos artículos (en breve la casi totalidad) están, a día de hoy, accesibles en www.laphenomenologierichirienne.org

Otro registro de discurso lo constituyen sus cursos, sus extraordinarias clases, de las que, como hemos señalado más arriba, la editorial Ellipses, consciente de la especificidad de ese registro en Richir, prepara una edición que constituirá un extraordinario complemento a sus libros y artículos. Richir, ni habla como escribe ni escribe como habla. Son ámbitos complementarios. Accesos distintos a lo mismo. La enseñanza que se ha de sacar de esto va dirigida a algunos de sus contemporáneos franceses que pretenden (diciéndolo, pero no firmándolo) que ahí no hay sino puro humo recubierto de un lenguaje artificiosamente complicado, sobrecomplejificado para enmascarar la falta de Sachlichkeit. Pues bien, lo que apuntamos ahora en punto al registro de los cursos y 
conversaciones aclaratorias es testimonio, en suma, de que sí hay Sachlichkeit. La prueba está en la diversidad de las vías de acceso. Así "eso" a lo que se accede por distintas vías es, por huidizo que sea, "algo" (y no simple humo como a veces se pregona). De ahí que las conferencias de Richir de un lado y sus cursos de otro (que se pondrán lento a lento a disposición en la mentada página web) constituyan también una extraordinaria puerta de entrada a su filosofía.

Un último registro lo forman las conversaciones, las entrevistas más o menos públicas o las aclaraciones en punto a su fenomenología que Richir pueda ofrecer, a título privado. Lo que siempre me ha sorprendido en ellas es la enorme precisión, el carácter no arbitrario, y la gran concreción fenomenológica que preside a estas conversaciones, por informales que sean. Cuando se le pregunta a Richir por algún aspecto difícil y aparentemente abstracto de sus escritos, responde siempre, oralmente, con algo concretísimo. Siempre hay una o varias experiencias concretas con que ilustrar un pasaje aparentemente abstracto de sus libros. Dicho de otro modo: para todo, para absolutamente todo, hay ejemplos, hay piedras de toque intuitivas. Todo lo que hay en sus escritos tiene su clara justificación con arreglo al "principio de todos los principios" enunciado en el $\S 24$ de Ideas $I$ (como no puede ser de otro modo en fenomenología).

Pues bien, esas apoyaturas intuitivas se explicitan en las conversaciones, muchas veces en los cursos. Ocurre, sencillamente, que es menos amigo de escribirlas, o de aludir a dichas intuiciones nombrándolas de modo concreto, a título de ejemplo, en sus textos escritos. No lo hace por la sencilla razón de que ello polarizaría en exceso la Sachlichkeit que se trata de captar en su tenor eidético ("eidético" dicho en sentido genérico, es decir, también esquemático). Efectivamente, cuando nos las habemos con registros de experiencia sumamente arcaicos, la invocación de cualquier ejemplo puede embarrar la Sache fenomenológica que se trata de explicitar, puede hacerlo importando elementos de otros registros. Los ejemplos, de ser aclaratorios, pueden muy rápidamente convertirse en Caballos de Troya de apercepciones que cierran y fijan el aspecto que el propio ejemplo trataba de acercar. Así, el ejemplo impone su lógica, sus implicaciones intencionales, y lo hace en detrimento de la concretísima y sutilísima cosa que se trataba de cercar y que el ejemplo sólo ejemplificaba en parte. En la fluidez de una conversación (más incluso que en una clase magis- 
tral o incluso en un seminario) cabe contrarrestar estos efectos espontáneamente totalizantes o metonímicos del ejemplo; hacerlo, por caso, con prevenciones, o con otros ejemplos que por intersección vayan decantando el concretísimo y sutilísimo respecto a sobrehaz del cual el ejemplo fungía como ejemplo. La escritura no goza de esta labilidad. Se halla impotente frente al modo en que, quiérase o no, la masividad de un ejemplo (un ejemplo dispara desde sí todo un horizonte aperceptivo) destempla y estría los registros arquitectónicos más sutiles; allí donde el más leve exceso, la más liviana imprecisión ya precipita una cristalización, ya se salda con fijezas y ángulos muertos, grumos aperceptivos que se agolpan y abultan, que generan transposiciones arquitectónicas que arrastran al fenomenologizar por derroteros que le apartan de la sutilísima sintonía mereológica de las concrescencias arcaicas, conduciéndolo por el diabólico perdedero de una falsa fecundidad (cuando la propia lógica de la metáfora tiraniza a la Sache fenomenológica). Falsas fecundidades que, andado el tiempo - y vacío el sedimento- se tornan en "quimeras" como diría Antonio Machado (punto, este último, que nombro porque le interesa sobremanera a Richir; efectivamente, es un aspecto clave de los primeros poemas de Machado; también de los poemas de Campos de Castilla más directamente inspirados de la pérdida que supuso para el poeta la muerte de Leonor).

En rigor, que los ejemplos puedan producir en ocasiones cristalizaciones indebidas pone de manifiesto que también hay, en suma, una concreción de la abstracción. La $2^{a}$ Investigación lógica y ciertas partes de la $6^{a}$ tienen, a este respecto, una enorme importancia para Richir, tal y como suele repetir en sus cursos $^{5}$. Esta concreción no es la de un todo concreto relativamente independiente sino, por así decirlo, la concreta dependencia de ciertos momentos que no son "nada sino partes" ${ }^{1}$, partes las más veces mucho más concretas que el todo concreto, relativamente independiente que por sí solo constituye, si no se lo decanta correctamente, un ejemplo. A este respecto, Sacha Carlson está elaborando un largo libro hecho de transcripciones de entrevistas con Marc Richir sobre aspectos de su obra. Creo que será esencial para la comprensión de la obra richiriana y constituirá cierta plasmación por escrito de ese registro oral tan esencial a la obra richiriana.

\footnotetext{
${ }^{5}$ Tal y como se ve, por caso, en el $2^{a}$ y la $3^{a}$ de sus Recherches Phénoménologiques. Cfr. Marc Richir, Recherches phénoménologiques (I, II, III), Bruxelles, Éditions Ousia, 1981.

${ }_{6}$ Cfr. Pablo Posada Varela "Concrétudes en concrescences", Annales de Phénoménologie 11 (2012).
} 


\section{RICHIR Y SU RECIENTE APERTURA A LA TRADICIÓN ESPAÑOLA}

Hay otro punto que creo que merece mención aparte. Es difícil captarlo en palabras y es algo que no he alcanzado a verbalizar sino hasta hace bien poco, siquiera como el enunciado de algo pendiente de ulteriores precisiones. Creo que radica en el hecho, palmario, de que a pesar de ser el francés la lengua materna de Richir, no es Richir francés sino belga, belga de origen valón, nacido en Charleroi y estudiante de física en Lieja (licenciatura y parte del doctorado en el laboratorio de Astrofísica) y luego estudiante de filosofía (licenciatura y doctorado) y más adelante profesor asociado ${ }^{7}$ en la Universidad Libre de Bruselas. ¿Qué quiere esto decir? ¿Qué interés puede tener esto para lo que nos ocupa y para la concreta ocasión de la publicación en español de tres textos cortos de Richir en la revista de la Sociedad Española de Fenomenología? Vayamos lento a lento y se verá la pertinencia de lo que decirnos.

De entrada, yo creo que este elemento de relativa distancia o no adherencia a lo franco-francés determina decisivamente su modo de hacer filosofía (de esto ya hemos hablado). Pero determina también un punto decisivo para nosotros (que tampoco somos franceses): no es otro que esa capacidad que siempre ha tenido Richir, tan limpia de instituciones, retórica, y rituales academicistas, para abrirse a otras tradiciones, ligero del peso de lo que, intelectual e institucionalmente, supone Francia. Creo que eso ha ayudado a la limpieza de su apertura a otras tradiciones literarias. En esa limpieza sorprende la falta de elementos mediadores. Cuántas veces habré oído en Francia elogios de Cervantes o de las Meninas de Velázquez que era elogios prestados, hechos de memoria de la mano de Foucault (que a su vez hace una lectura muy parcial de esos elementos de la cultura española). Esto es algo que, en cambio, no se daba en Lévinas donde también se percibe la pertenencia a una cultura distinta (se ve en el modo genial en el que Lévinas trae, a veces, pasajes del Quijote). Ahora bien, lo sorprendente en Richir es que esta apertura no se reduce simplemente a la literatura o al arte. Es también genuina su apertura a la tradición filosófica

\footnotetext{
7 El estatuto es, más bien, el de "chargé de cours", estatuto que tienen algunos profesores del FNRS belga (lo equivalente a nuestro CSIC), institución que constituía la principal vinculación de Richir. 
española (pues no tiene ningún sentido hablar de "tradiciones científicas", al menos en el sentido en el que aquí usamos "tradición"). Huelga decir que eso sí que es, en un intelectual francófono, y como todo intelectual español sufre y sabe, poco menos que excepcional, cuando no milagroso.

Efectivamente, ese rasgo de apertura de Richir a la tradición española, apertura no sólo folclórica y antropológica, literaria o artística, es, para nosotros, de enorme incumbencia, no tanto por un estúpido patriotismo sino por la muy española tradición intelectual de despreciar por sistema todo lo español (rasgo que, por cierto, le sorprende muchísimo a Richir: esa suerte de harakiri continuo que el intelectual español hace de lo valioso de su pasado).

En punto a la tradición española de pensamiento (arte y literatura) no es exagerado decir que Richir, de unos siete u ocho años a esta parte, se ha convertido, a su manera (manera que poco tiene, claro está, de filológica), en un consumado especialista. A su manera, es decir, siempre en el contexto creativo de su obra. De todas la maneras, ésta es, huelga decir, la mejor para acceder a algo, la que lo ofrece con mayor riqueza, la que lo hace hablar de veras y hace de lo leído, de lo comprendido, acervo definitivo, definitivamente integrado por haberse incorporado, por volverse recurrentemente ejecutivo, "parte", si se quiere, de la Leiblichkeit transcendental de un pensador. Consumado especialista, decíamos, creo que sin ápice de exageración ni traición alguna a la verdad infundida desde complejos de inferioridad propios (acaso los de todo desterrado español) trocados en deseos o forzamientos. Consumado especialista a pesar de no hablar español y sólo leer en traducción.

Las muchísimas lecturas que Richir ha hecho de autores españoles apenas si empiezan a trasparecer, ahora, en sus textos (lecturas de textos recónditos como Las aventuras del capitán Alonso de Contreras o algunos textos de Max Aub, por no hablar de clásicos como La vida es sueño, La Celestina, o El Buscón). Que, a pesar de las muchas lecturas, ello no se note de forma directa en los textos bajo la forma de una nota al pié se debe a que Richir es enormemente cauto en las citas. Por poner un ejemplo, sorprende que apenas si haya un texto de Shakespeare citado en exergo en los Fragments phénoménologiques sur le langage (2008) cuando Richir ha leído y releído a Shakespeare hasta la saciedad. Otro tanto ocurre con Stendhal o con Baudelaire, que Richir conoce casi de memoria. Por eso, la malhadada -por comprensible desconocimiento- o a veces malintencionada -por llana maldad-crítica que se sorpren- 
de o en ocasiones porfía en punto al hecho de que Richir sólo se cite a sí mismo (lo cual ni siquiera en su nuda literalidad es exacto) no puede ser más injusta. Eso he podido comprobar al correr de los años y a tenor de un contacto más directo con él. Otro caso de lo mismo es su profundo conocimiento de Goya (una reproducción del cuadro del perro hundiéndose cuelga a espaldas de su mesa de trabajo). Tal es el solemne respeto que Goya suscita en él que considera que ningún comentario que él pudiera hacer sabría hacerle justicia al genio de Fuendetodos.

Sea como fuere, el contraste con sus colegas filósofos franceses es flagrante. $Y$ eso que en Francia ha habido valiosísimos hispanistas; pero no hablamos aquí de ellos. Hablamos más bien del filósofo tipo francés (más aún del gran catedrático ${ }^{8}$ ), al que caracteriza un especial desdén por cualquier tipo de producción intelectual española. En aquél, el interés por ésta se reduce a lo que es meramente folclórico. No me imagino -por poner las cosas más claras- a uno de los grandes popes filosóficos o "fenomenológicos" de la Sorbona recorriendo apasionado las páginas del Juan de Mairena de Antonio Machado, o La agonía del Cristianismo de Unamuno, obras y autores por los que Richir siente enorme respeto cuando no declarada devoción. Hablo de recorrer esas páginas, repito, no por curiosidad folclórica, sino con el ánimo y propósito sinceros de encontrar algo distinto e inaccesible por otras vías, y hacerlo con la convicción de estar aprendiendo algo nuevo y decisivo.

Efectivamente, en Richir habita la hiperbólica sospecha de que quizá en otras tradiciones se embosque una clave para entender la experiencia del humano estar en el mundo, experiencia que, como tal experiencia, es de todos los humanos y por ende base de toda institución simbólica. Eso le lleva a buscar, según coordenadas ajenas, una clave que, desde tradiciones que le son

\footnotetext{
${ }^{8}$ Hay honrosas excepciones que, claro está, no vienen de los grandes popes o mandarines de la fenomenología francesa. Citemos, por ejemplo, el valioso esfuerzo que desde hace un tiempo acomete un grupo de trabajo respecto de la obra de Xavier Zubiri, de la que han aparecido últimamente muchísimas traducciones en la editorial L'Harmattan. Otro ejemplo (que, por desgracia, "contiene" su contraejemplo) está en la magnífica traducción al francés que se ha hecho de El hombre y la gente de Ortega (uno de los libros de Ortega favoritos de Richir, junto con La idea de principio en Leibniz, el Velázquez, algunos textos sobre el Imperio Romano, algunos textos cortos (como el Mirabeau o el político o el Pidiendo a un Goethe desde dentro) y En torno a Galileo; libro, este de El hombre y la gente que, a día de hoy, aconseja para acercar fenomenológicamente la cuestión de la Institución Simbólica). Sin embargo -y aquí viene el contraejemplo, literalmente "contenido" "en las páginas" del ejemplo- la edición de L'homme et les gens (Paris, Eds. rue d'Ulm, 2008) contiene, aparte de esa magnífica traducción, un repugnantemente injusto prólogo (que indignó bastante al propio Richir) del profesorón de turno (que, por supuesto, no participó en la traducción) donde, por desgracia para el enorme trabajo del equipo de traducción, vuelven a salir a flote todos los prejuicios del intelectual francés sobre España y, sobre todo, sobre las producciones intelectuales de que España es capaz.
} 
más cercanas (como la francesa o la alemana), es clave recubierta, punto ciego o ángulo muerto. Y puede que la "tradición" belga (tanto flamenca, como valona y belga germanófona) resida, por cierto, no sólo en una determinada "tradición" sino antes bien en ese haber estado a caballo entre varias (entre las que se cuenta, por cierto, la española), en haber estado "en falso" (en "porte-àfaux" como dice Richir) respecto de cada una de ellas por estar la tradición intelectual de Bélgica encabalgada (el "enjambement" del que también nos habla Richir) sobre otras sin hacer del todo pie en nada. Puede que de su tradición le venga el no coincidir del todo con ninguna, puede que esa no adherencia de la experiencia a sus "creencias" sea lo que constituye el legado extraño de esa variopinta tradición propia de Bélgica ${ }^{9}$ que, como la propia reducción, no crea "hábito" en sentido estricto, sino más bien el "hábito", en derivada segunda, de desenclavarlo todo, de que nada sea a pie fijo, de que todo, a pique de ser suspendido, tome el sano cariz de lo variopinto.

Sea como fuere, muy lejos estamos aquí de la masiva presencia del Panteón parisino y del lema que lo corona: "Aux grands hommes la patrie reconnaissante", muy lejos de los códigos infinitos, muchas veces hueros, que se estilan en la "École Normale Supérieure" o en las "Grandes Écoles" en general $^{10}$. Sólo así, horro de esas férulas francofrancesas, puede entenderse (entenderse, claro está, en parte: la otra parte la pone la irreductible singularidad de cada individuo) el sincero esfuerzo de acceso, por parte de Richir, a esa extraña tradición, esquina de Europa, que es la española. Es así que he visto a Richir leer el Quijote por tercera vez, leyéndolo, esa vez tercera, con el abismal Vida de Don Quijote y Sancho de Unamuno (y no Les mots et les choses de Foucault, infumable en muchos aspectos) abierto a la vera de la obra de Cervantes, o también bucear no sólo en El romancero gitano de García Lorca sino en cosas muy precisas y recónditas como, por ejemplo, las prosas de juventud en las

\footnotetext{
${ }^{9}$ Esto es algo que, evidentemente, se está perdiendo hoy en día, donde todo adquiere un oscuro tinte de barbarismo y reclamo de pertenencia al terruño. Algo muy triste. No sólo en Bélgica. Es algo que, por desgracia, nos toca a los españoles muy de cerca.

${ }^{10}$ Antiguo alumno del Liceo Francés de Madrid como soy, son cosas que conozco muy de cerca. Lo conozco en sus bondades y en sus malsanas disfunciones. Disfunciones a veces dramáticas, capaces, por cierto (lo he visto en amigos relativamente cercanos) de llevarse vidas enteras por delante, imaginariamente marradas por el hecho, en el fondo extrínseco y sobredimensionado, de no haber conseguido entrar en la École Normale Supérieure tras haberlo intentado varias veces o haber suspendido la agregación de filosofía en repetidas ocasiones tras empecinarse en intentarlo. Disfunciones menos dramáticas en la figura de jóvenes filósofos muy brillantes que no son más que eso: brillantes y, desde luego, extraordinarios profesores, pero perdidos (donde acaso sí fueron capaces) para el largo aliento, el esfuerzo sostenido, que una verdadera obra requiere.
} 
que el poeta de Granada (por ejemplo en Impresiones y paisajes) hace descripciones sobrecogedoras no sólo de paisajes sino de paisajes con sus formas de vida (por ejemplo de vida monacal en Las Dueñas). Le he visto leer en traducción alemana textos de Ortega no disponibles traducción francesa. De hecho, eso explica la historia de la traducción francesa del Ensayo de estética a manera de prólogo que leyó Richir gracias a la meritoria edición, a cargo de Javier San Martín, de Schriften zur Phänomenologie. O de Vitalidad, alma, espíritu y de Sobre la expresión, fenómeno cósmico, incluidos ambos en la edición en seis tomos de la obras de Ortega que se ha hecho en alemán en la Deutsche Verlags-Anstalt (Stuttgart/München 1996). Fueron textos a los que Richir sólo había accedido por la traducción alemana. Textos de los que, de resultas de su lectura, alentaría más tarde una traducción -inédita hasta entonces en francésen los números 10 (2011) y 11 (2012) de Annales de Phénoménologie (www.annalesdephenomenologie.org). Eso por citar sólo algunos autores (entre los que habría que contar también a Quevedo, Calderón, Huarte de San Juan y otros). Algo parecido (traducir y publicar a través de Annales de Phénoménologie o en la editorial Krisis) está en curso con Idea del teatro de Ortega o las lecciones de 1915-1916 que Paulino Garagorri llamó de Psicología. Otro tanto respecto de algunos textos cortos de Antonio Machado sobre la lírica y la poesía. Textos de Los complementarios y de De un cancionero apócrifo, inéditos en francés, y de los que he hecho yo mismo traducciones parciales y provisionales que he discutido y revisado con el propio Richir.

\section{LA RECEPCIÓN DE RICHIR EN ESPAÑA}

Esto entronca con la cuestión inversa, a saber, la cuestión de la recepción de Richir en España, recepción en la que, sin lugar a dudas, jugará este número de Investigaciones fenomenológicas un importantísimo papel. Esta recepción se hizo, en primer término, a través de Javier San Martín. Fue Javier San Martín, en calidad, a la sazón, de presidente de la SEFE, quien tuvo la feliz (al menos para mí...) iniciativa de invitar a Richir (junto a Guy van Kerckhoven) en septiembre de 1998, a dar una conferencia en el marco de un pequeño congreso. De hecho, debo a Javier San Martín y a la ocasión de este congreso de la SEFE el haber conocido personalmente a Richir. Efectivamente, Javier San Martín 
había coincidido con Richir en algunos congresos internacionales sobre Husserl o en torno a la figura de Fink (por ejemplo en el célebre coloquio sobre Fink de Cérisy-la-Salle del 23 al 30 de julio de 1994) y había trabado conocimiento y amistad con él desde hacía cierto tiempo. De ese contacto nos aprovechamos todos. Yo, claro está, el primero. Esa primer contacto de San Martín con Richir en algunos congresos internacionales fue la semilla que tuvo su fruto en la invitación que San Martín, en nombre de la SEFE, cursó a Richir; iniciativa que, desde luego, ha terminado siendo de gran provecho para mí, y de mucha importancia para mi biografía intelectual.

La segunda venida de Richir tuvo otro ámbito de recepción. Terminó cristalizando en un congreso de dos semanas en torno a la fenomenología arquitectónica de Marc Richir organizado, en septiembre de 2010, por la universidad de Oviedo (de la mano del profesor Alberto Hidalgo) y de la Sociedad Asturiana de Filosofía (de la mano de Román García y Silverio Sánchez Corredera entre otros, pero fundamentalmente de la mano $-\mathrm{y}$ enorme, incansable generosidadde Pelayo Pérez García). Decisivo al efecto fue el curso que en mayo de 2009, también en Oviedo y amparado también por la Sociedad Asturiana de Filosofía, había impartido Ricardo Sánchez Ortiz de Urbina, lector de Richir desde hace muchos años.

En ese curso de mayo del 2009 presentó Urbina su versión de la fenomenología. Hizo en ella un uso originalísimo de ciertos elementos de la fenomenología de Richir, ampliando aspectos decisivos (problemáticos y aporéticos) del materialismo filosófico de su maestro, Gustavo Bueno. Digamos que Richir prendió, en Oviedo, en un núcleo de antiguos discípulos de Gustavo Bueno (siendo Urbina e Hidalgo discípulos de las primerísimas generaciones). Discípulos que habían tomado ciertas vías heterodoxas ${ }^{11}$ respecto de la gran obra filosófica que constituye el sistema del materialismo filosófico de Bueno y su imponente teoría del cierre categorial. Al hilo de esa visita, se han publicado dos números especiales sobre Richir (34 y 40) en la revista Eikasia.

\footnotetext{
${ }^{11}$ Otro ejemplo de divergencia respecto del materialismo filosófico de Bueno es la interesantísima obra filosófica en curso de Fernando Pérez Herranz, muy interesado también en la obra de Richir. Mientras que la divergencia de Pérez Herranz respecto del materialismo de Bueno podría caracterizarse como una suerte giro morfológico (que hace un uso extraordinariamente interesante de la topología y de la teoría de catástrofes de René Thom), la divergencia de Urbina representa un giro fenomenológico de materialismo filosófico de Bueno. Giro fenomenológico que se entiende como ampliación, y que hace un uso muy fecundo de la fenomenología de Richir.
} 
Acceder a la obra de Richir requiere cierto esfuerzo, pero los réditos, creemos, lo merecen. Sólo me queda esperar que los artículos de y sobre Richir, presentes en este volumen de Investigaciones fenomenológicas, así como las notas a las traducciones, balicen en lo posible ese acceso. Esa primera semilla que, en septiembre de 1998, plantara la iniciativa de J. San Martín y de la SEFE de traer Richir a España tiene, aquí y ahora, en este número de Investigaciones fenomenológicas, un fruto ulterior (de tantos que ha tenido entretanto), fruto ulterior que, seguramente, no será el último. Esperemos, en cualquier caso, que este fruto de ahora, fruto de la semilla de aquel entonces, sea semilla para frutos futuros florecidos en otras biografías intelectuales.

Paris, junio de 2012. 